\title{
Pramlintide acetate
}

National Diabetes Information Clearinghouse (NDIC)

\section{Definitions}

Diabetes

Defined by National Diabetes Information Clearinghouse (NDIC)

Glucose

Defined by National Diabetes Information Clearinghouse (NDIC)

Liver

Defined by National Diabetes Information Clearinghouse (NDIC)

Amylin mimetic

Defined by National Diabetes Information Clearinghouse (NDIC)

\section{Source}

National Diabetes Information Clearinghouse (U.S.). (2009). The diabetes dictionary. [Bethesda, Md.]: U.S. Dept. of Health and Human Services, National Institutes of Health, National Institute of Diabetes and Digestive and Kidney Diseases,

National Diabetes Information Clearinghouse.

An injectable medicine used to treat diabetes. Pramlintide helps food move more slowly through the stomach and helps keep the liver from releasing stored glucose. Pramlintide belongs to the class of medicines called amylin mimetics. (Brand name: Symlin.) 